\title{
G-Protein-Gated Potassium (GIRK) Channels Containing the GIRK2 Subunit Are Control Hubs for Pharmacologically Induced Hypothermic Responses
}

\author{
Alberto C. S. Costa, ${ }^{1,2}$ Melissa R. Stasko, ${ }^{1}$ Markus Stoffel, ${ }^{3}$ and Jonah J. Scott-McKean ${ }^{1}$ \\ ${ }^{1}$ Eleanor Roosevelt Institute, University of Denver, Denver, Colorado 80206, ${ }^{2}$ Department of Psychiatry, University of Colorado Health Science Center, \\ Denver, Colorado 80262, and ${ }^{3}$ Laboratory of Metabolic Diseases, Rockefeller University, New York, New York 10021
}

\begin{abstract}
Hypothermic responses of rodents to the peripheral or intraventricular injection of many individual neurotransmitter receptor agonists have been well documented. Because many hypothermia-inducing agonists are also known to activate G-protein-gated potassium (GIRK) channels, we investigated the hypothermic response to several of these agents on Girk2 null mutant mice. Core body temperatures were measured through radiotelemetry, and animals were maintained in special temperature-regulated chambers to ensure the accuracy of the measurements. The resulting data indicate that the activation of GIRK2-containing potassium channels plays a significant role in hypothermia induced by the activation of serotonergic $\left(5-\mathrm{HT}_{1 \mathrm{~A}}\right), \mathrm{GABAergic}\left(\mathrm{GABA}_{\mathrm{B}}\right)$, muscarinic $\left(\mathrm{m}_{2}\right)$, adenosine $\left(\mathrm{A}_{1}\right)$, and $\mu, \delta$, and $\kappa$ opioid receptors. These channels also are involved in the alcohol-induced hypothermic response. These results have implications for the understanding of pharmacologically induced hypothermia and thermoregulatory mechanisms.
\end{abstract}

Key words: hypothermia; GPCR; 5- $\mathrm{HT}_{1 \mathrm{~A}}$ receptor; $\mathrm{GABA}_{\mathrm{B}}$ receptor; muscarinic; dopaminergic; adrenergic; adenosine; opioid; alcohol; potassium channels; Down syndrome

\section{Introduction}

G-protein-gated potassium (GIRK) channels are modulated by a variety of G-protein-coupled neurotransmitter receptors (GPCRs), including serotonergic $\left(5-\mathrm{HT}_{1 \mathrm{~A}}\right)$, GABAergic $\left(\mathrm{GABA}_{\mathrm{B}}\right)$, muscarinic $\left(\mathrm{m}_{2}\right)$, adenosine $\left(\mathrm{A}_{1}\right)$, opioid $(\mu, \delta$, and $\kappa)$, adrenergic $(\alpha 2)$, and dopaminergic $\left(D_{2}\right)$ receptors (for review, see Yamada et al., 1998). GIRK channels play key roles in the maintenance of the resting membrane potential, regulation of action potential duration, and receptor-dependent modulation of cellular excitability. GIRK1/GIRK4 heteromers are found mainly in the atrium (Krapivinsky et al., 1995). Neuronal cells predominantly express GIRK1, GIRK2, and GIRK3 but also express GIRK4 to a minor extent (Wickman et al., 2000). When activated, GIRK channels typically decrease the firing rate of atrial myocytes and neuronal cells. Interestingly, the pharmacological activation of the same GPCRs that are known to positively modulate GIRK channels also produces hypothermia in rodents (Jackson and Nutt, 1991; Meller et al., 1992; Anderson et al., 1994; Malberg and Seiden, 1997; Heisler et al., 1998; Gainetdinov et al., 1999; Millan et al., 2000; Eltayb et al., 2001; Baker and Meert, 2002).

To explore the potential connection between GPCR activation of GIRK channels and pharmacologically induced hypothermia,

Received April 28, 2005; revised July 15, 2005; accepted July 19, 2005.

This work was supported by National Institutes of Health Grants HD37113 and HD37424.

Correspondence should be addressed to Dr. Alberto Costa, Eleanor Roosevelt Institute, University of Denver, 1899 Gaylord Street, Denver, C0 80206. E-mail: acosta@du.edu.

DOI:10.1523/JNEUROSCI.1699-05.2005

Copyright $\odot 2005$ Society for Neuroscience $\quad$ 0270-6474/05/257801-04\$15.00/0 we quantitatively assessed the hypothermic responses of inbred Girk2 null mutant [knock-out (KO)] mice to the peripheral injection of several selective GPCR agonists and ethanol. Core body temperatures were measured through radiotelemetry, and animals were maintained in special temperature-regulated chambers to ensure the accuracy of the measurements. The Girk2 gene (also known as Kcnj6, Kir3.2, or "weaver gene") encodes potassium channel subunits that are thought to form primarily heteromeric channels with GIRK1 subunits, and Girk2 KO mice also show reduced Girk1 expression in the brain (Signorini et al., 1997). Therefore, Girk2 KO mice are deficient on two of the three major neuronal GIRK channel subunits and should provide a reasonable initial estimate of the role of GIRK channels in pharmacologically induced hypothermia.

\section{Materials and Methods}

Animals. The generation and DNA PCR genotyping of Girk2 null mutant mice were described by Signorini et al. (1997). Heterozygous Girk2 KO mice were backcrossed 15 generations onto the C57BL/6J background to effectively eliminate variations in genetic background. Experimental animals were generated by heterozygous $X$ heterozygous matings, which produced homozygous, heterozygous, and wild-type mice. Mice were group-housed four to five to a cage based on sex and litter until the day they underwent surgical implantation of miniature telemetry devices and were single-housed thereafter. Animals were maintained on a $12 \mathrm{~h} \mathrm{light/}$ dark cycle, with lights on at 7:00 A.M. and ad libitum access to food and water. All experiments were performed during the light phase of the light/dark cycle. Altogether, 60 male mice were used in this study: 24 wild-type, 24 homozygous KO, and 12 heterozygous KO mice. Handling and care of mice were consistent with federal guidelines, and all experi- 
mental methods received the approval of the University of Denver's Animal Care and Use Committee.

Core temperature measurements. To quantitatively assess core temperature drops, we performed the temperature measurements with temperature-sensitive radiotelemetry devices (XM-FH; Mini Mitter, Sun River, OR) surgically implanted in the mouse peritoneal cavity under general anesthesia $(80 \mathrm{mg} / \mathrm{kg}$ ketamine and $20 \mathrm{mg} / \mathrm{kg}$ xylazine, i.p.). After a 3-4 $\mathrm{d}$ recovery period, the animals were transferred in their home cage into a temperature-measurement chamber for 110-150 $\min$ (set at $24 \pm$ $0.2^{\circ} \mathrm{C}$ ), similar to the one described by Malberg and Seiden (1997). First, the mice were acclimated to the temperature chamber for $30 \mathrm{~min}$ before the injection of the drug. Then, after drug administration, core body temperatures were recorded continuously for an additional 80-120 min period. Injections were performed twice per week for 4 consecutive weeks on the same animals. These procedures were designed to minimize confounding factors such as core body temperature shifts attributable to animal handling or fluctuations in room temperature.

Preparation and administration of drugs. Subcutaneous injections of the selective 5- $\mathrm{HT}_{1 \mathrm{~A}}$ and $5-\mathrm{HT}_{7}$ receptor agonist $R-(+)-8$-hydroxy-2(di- $n$-propylamino) tetralin (8-OH-DPAT) were used to study the dose dependence of the hypothermia induced by this compound on wild-type, homozygous KO, and heterozygous KO mice. Single-dose 8-OH-DPAT injections were performed twice per week for 4 consecutive weeks on the same animals in the following sequence of doses: $0.1,1.0,0.03,0.3,3.0,0$, and $10 \mathrm{mg} / \mathrm{kg}$; this was designed to prevent the development of tolerance (Meller et al., 1992). The role of the Girk2 gene on the hypothermia induced by various GPCR agonists was studied on a second group of wild-type and homozygous $\mathrm{KO}$ mice. The agonists used were 8-OHDPAT $(0.3 \mathrm{mg} / \mathrm{kg}$, s.c.), ( $R$ )-4-amino-3-(4-chlorophenyl) butanoic acid (baclofen; $\mathrm{GABA}_{\mathrm{B}}$ receptor; $5 \mathrm{mg} / \mathrm{kg}$, i.p.), oxotremorine $\left(\mathrm{m}_{2}\right.$ receptor; $0.05 \mathrm{mg} / \mathrm{kg}$, s.c.); $R$-(+)-7-hydroxy-2-(di- $n$-propylamino) tetralin (7OH-DPAT; $D_{2 / 3}$ receptor; $0.2 \mathrm{mg} / \mathrm{kg}$ s.c.), clonidine ( $\alpha 2$ adrenergic receptor; $0.2 \mathrm{mg} / \mathrm{kg}$, s.c.), $R-N^{6}$-phenylisopropyloadenosine (R-PIA; $\mathrm{A}_{1}$ receptor; $0.05 \mathrm{mg} / \mathrm{kg}$, i.p.), 4 -( $p$-chlorophenyl)-4-hydroxy- $N, N$ dimethyl- $\alpha, \alpha$-diphenyl-1-piperidinebutyramide (loperamide; opioid $\mu$, $\delta$, and $\kappa$ receptor; $5 \mathrm{mg} / \mathrm{kg}$, i.p.), and ethanol ( $3 \mathrm{~g} / \mathrm{kg}$, i.p.), which has been shown to directly activate GIRK2-containing channels (Lewohl et al., 1999) as well as 5-HT $\mathrm{HA}_{1 \mathrm{~A}}$ receptors (Popova and Ivanova, 2002). Except for ethanol, all drugs were purchased from Sigma (St. Louis, MO), were prepared from frozen stocks $\left(-80^{\circ} \mathrm{C}\right)$ on the day of the experiments, and were administered at an injection volume of $6.25 \mathrm{ml} / \mathrm{kg}$. A $20 \% \mathrm{w} / \mathrm{w}$ solution of ethanol in physiological saline $(0.9 \% \mathrm{NaCl}$ in distilled water $)$ was prepared from a 95\% stock (AAPER Co., Selbyville, KY; kept at $-20^{\circ} \mathrm{C}$ ) on the day of the experiments and administered at an injection volume of $15.66 \mathrm{ml} / \mathrm{kg}$.

Statistics. Basal core temperature values for each genotype were compared by one-way ANOVA (Statistica 6.1; StatSoft, Tulsa, OK). In experiments involving the study of the dose dependence of the hypothermia induced by $8-\mathrm{OH}-\mathrm{DPAT}$, we generated dose-response graphs in which data points represented mean \pm SEM maximal temperature drop values for each animal per genotype per dose as a function of the 8-OH-DPAT dose. These results were analyzed by two-way repeated-measures (RM) ANOVA and Fisher's protected least significant difference (PLSD) post hoc tests, with dose and genotype as factors (Statistica). In addition, these data were curve fitted to a Hill equation $[Y=$ MaxResponse/ $(1+$ $\exp \left[\left(\log \mathrm{ED}_{50}-X\right) \times\right.$ HillSlope $\left.]\right)$, where $X$ is the logarithm of the $8-\mathrm{OH}$ DPAT dose, $Y$ is the magnitude of the temperature drop, MaxResponse represents the maximal curve asymptote, $\log \mathrm{ED}_{50}$ is the logarithm of the 8-OH-DPAT dose that produces one-half the maximal response, and Hillslope represents the steepness of the dose-response curve] using nonlinear regression (Prism version 4; GraphPad Software, San Diego, $\mathrm{CA}$ ). The values of parameters MaxResponse, $\log \mathrm{ED}_{50}$, and HillSlope for each genotype were compared by $F$ tests. Unpaired two-tailed MannWhitney $U$ tests (Prism) were used to compare the mean temperature drops produced by various GPCR agonists on wild-type versus homozygous $\mathrm{KO}$ mice. In all cases, a difference was considered to be significant if the obtained probability was $p<0.05$.
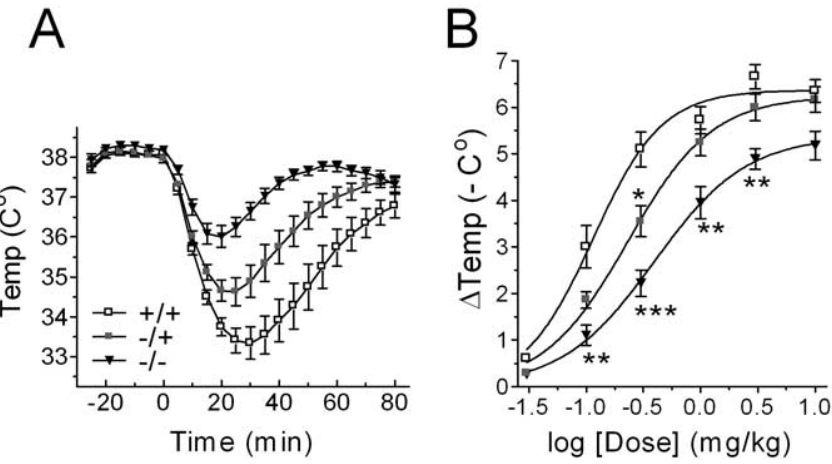

Figure 1. Girk2 gene dosage has a significant effect on the amount of hypothermia induced by $8-0 \mathrm{H}-\mathrm{DPAT}$. $\boldsymbol{A}$, Mean \pm SEM core body temperature drops elicited by injections of $8-\mathrm{OH}-$ DPAT in wild-type mice $(+/+$; open squares), heterozygous Girk2 K0 mice $(-/+$; shaded squares), and homozygous Girk2 K0 mice ( $-/-$; filled triangles) ( $n=12$ for each group of animals) plotted against time. Time $=0$, the time immediately before drug injection. $\boldsymbol{B}$, Doseresponse relationships for the maximal drops \pm SEM in core temperature produced by $8-0 \mathrm{H}-$ DPAT. Curves represent best fit variable slope sigmoidal dose-response curves. ${ }^{*} p<0.05$; ${ }^{* *} p<0.01$; ${ }^{* * *} p<0.001$.

\section{Results}

\section{Girk2 gene dosage has a significant effect on the amount of hypothermia induced by 8 -OH-DPAT}

Overall, we found progressively smaller temperature drops as the gene dosage of the Girk2 gene went from 2 in wild-type mice to 0 in homozygous Girk2 KO mice (Fig. 1A,B). Analysis of the data showed that both genotype (RM ANOVA; $F_{(2,33)}=22.137 ;{ }^{\star} p<$ $0.0001)$ and 8 -OH-DPAT dose $\left(F_{(5,165)}=279.63 ;{ }^{\star} p<0.0001\right)$ had significant $\left(^{*}\right)$ effects on the recorded core temperature drops. A significant interaction between genotype and 8-OHDPAT dose was also detected $\left(F_{(10,165)}=3.793 ;{ }^{\star} p=0.0001\right)$. In addition, Fisher's PLSD post hoc tests showed that the temperature drop induced by a $0.3 \mathrm{mg} / \mathrm{kg}$ injection of $8-\mathrm{OH}-\mathrm{DPAT}$ was larger for wild-type mice compared with heterozygous $\mathrm{KO}$ mice $\left.{ }^{*} p=0.0152\right)$ and larger for heterozygous $\mathrm{KO}$ mice than for homozygous KO mice $\left({ }^{\star} p=0.0350\right)$, which indicates a Girk2 gene dosage dependence for this form of pharmacologically induced hypothermia. Note, however, that the mean basal core body temperatures (as measured at time $=0$ ) were not significantly different across genotypes (wild-type, $38.07 \pm 0.08^{\circ} \mathrm{C}$; heterozygous $\mathrm{KO}, 37.97 \pm 0.10^{\circ} \mathrm{C}$; homozygous $\mathrm{KO}, 38.20 \pm$ $0.07^{\circ} \mathrm{C} ; F_{(2,33)}=1.887 ; p=0.1676$; ANOVA).

Although it is not possible to interpret in molecular terms the parameters of dose-response curves in the context of this type of experiment, nonlinear analysis of the best-fit Hill equations depicted in Figure $1 B$ indicates a significant decrease in apparent drug potency as the Girk2 gene dosage decreased from 2 in wildtype mice to 0 in homozygous Girk $2 \mathrm{KO}$ mice. The $\mathrm{ED}_{50}$ value for the hypothermia produced by 8 -OH-DPAT on wild-type mice $(0.115 \pm 0.014 \mathrm{mg} / \mathrm{kg})$ was significantly smaller than on heterozygous $\mathrm{KO}$ mice $\left(0.231 \pm 0.022 \mathrm{mg} / \mathrm{kg} ; F_{(1,6)}=15.57 ;{ }^{\star} p=\right.$ 0.0076 ; $F$ test $)$ and significantly smaller on heterozygous $\mathrm{KO}$ mice than on homozygous $\mathrm{KO}$ mice $\left(0.394 \pm 0.028 \mathrm{mg} / \mathrm{kg} ; F_{(1,6)}=\right.$ $\left.18.63 ;{ }^{\star} p=0.0050\right)$. The maximal hypothermic responses and Hill coefficients, however, were comparable between all three genotypes $\left(F_{(2,9)}=3.556, p=0.0728 ; F_{(2,9)}=1.456, p=0.2832\right)$.

\section{The Girk2 gene plays a significant role in the hypothermia induced by various GPCR agonists}

We then extended these experiments to a new group of Girk2 KO $(n=12)$ and control $(n=12)$ mice by injecting, in addition to 


\section{A B}
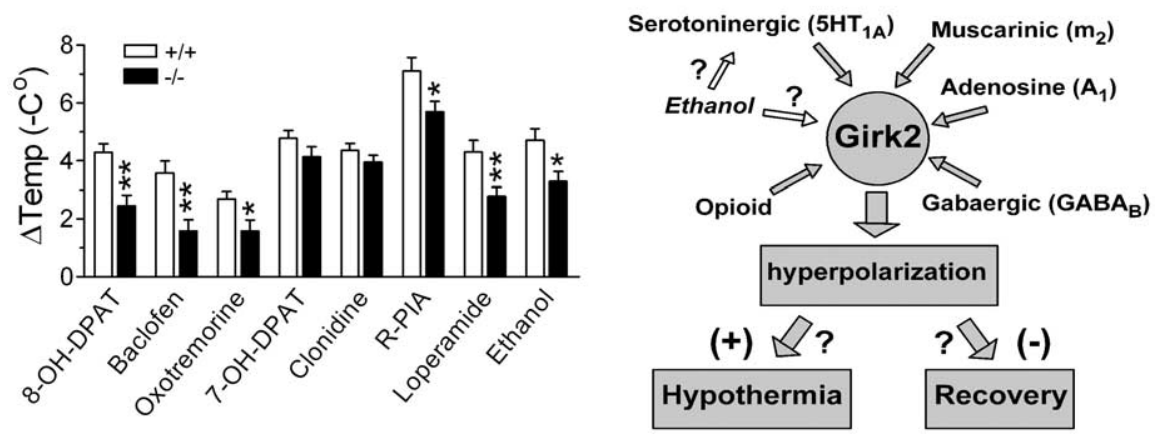

Figure 2. The Girk2 gene plays a significant role in the hypothermia induced by various GPCR agonists. $\boldsymbol{A}$, Maximal core temperature drops \pm SEM elicited by $8-0 \mathrm{H}-\mathrm{DPAT}$, baclofen, oxotremorine, $R$-PIA, loperamide, and ethanol in wild-type mice $(+/+$; open bars) and homozygous Girk2 KO mice ( $-/-$; filled bars) $(n=12$ for each group of animals). $\boldsymbol{B}$, Schematic model showing GIRK2-containing channels functioning as "molecular control hubs" for the hypothermia-inducing action of many GPCRs. ${ }^{*} p<0.05 ;{ }^{* *} p<0.01$.

8-OH-DPAT (0.3 mg/kg, s.c.), other GPCR agonists with demonstrated hypothermic effect. These agonists were baclofen $(5$ $\mathrm{mg} / \mathrm{kg}$, i.p.), oxotremorine (0.05 mg/kg, s.c.), 7-OH-DPAT $(0.2$ $\mathrm{mg} / \mathrm{kg}$, s.c. $)$, clonidine (0.2 mg/kg, s.c.), $R$-PIA ( $0.05 \mathrm{mg} / \mathrm{kg}$, i.p. $)$, loperamide ( $5 \mathrm{mg} / \mathrm{kg}$, i.p.), and ethanol (3 g/kg, i.p.). We observed significant genotype dependence for the amount of hypothermia produced by 8 -OH-DPAT $\left({ }^{*} p=0.0073\right.$; Mann-Whitney $U$ test $)$, baclofen $\left({ }^{*} p=0.0011\right)$, oxotremorine $\left({ }^{*} p=0.0226\right)$, $R$-PIA $\left({ }^{\star} p=0.0226\right)$, loperamide $\left({ }^{\star} p=0.0086\right)$, and ethanol $\left.{ }^{*} p=0.0166\right)$, whereas the results for 7-OH-DPAT $(p=0.1572)$ and clonidine $(p=0.4025)$ were not significantly genotype dependent (Fig. $2 A$ ).

In the present study, we made no systematic attempt to quantify behavioral events that typically accompany pharmacologically induced hypothermia, such as reduced locomotor activity and sedation. However, we noticed that these effects were also markedly less pronounced in homozygous $\mathrm{KO}$ mice, particularly after the injection of baclofen, 8-OH-DPAT, oxotremorine, and $R$-PIA.

\section{Discussion}

The main finding of the present study was that the Girk2 gene plays a significant role in the hypothermia induced by various GPCR agonists. Given that GIRKs are final common effectors for many central neurotransmitter systems, the simplest model accounting for these observations is one in which GIRK2containing channels act as molecular hubs controlling many modalities of pharmacologically induced hypothermic responses (Fig. 2 B). Although the present study has identified several neurotransmitter receptors that use GIRK2-containing channels as part of their hypothermia pathway, more studies will be necessary to produce a more comprehensive list, including assessments of dose-response relationships for each agonist being investigated. Also, the presence of substantial residual pharmacologically induced hypothermia in homozygous KO mice for all tested agonists clearly indicates that the activation of GIRK2-containing channels is only partially associated with the observed core temperature drops. This residual hypothermia may be the result of the activation of other members of the GIRK family. For example, Torrecilla et al. (2002) have shown that opioid-induced hyperpolarizations and whole-cell currents were reduced by $40 \%$ in locus ceruleus neurons from Girk $2 \mathrm{KO}$ mice and by $80 \%$ in neurons from Girk2/Girk3 double KO mice.
Although the basic mechanisms of neuronal thermosensitivity remain unresolved, most researchers in this field agree that the firing rate of warm-sensitive neurons in the preoptic-anterior hypothalamus is important in sensing changes in core temperature and controlling both physiological and behavioral thermoregulatory responses (Zhao and Boulant, 2005). Warming of the body increases the firing rate of these neurons. The majority of the spontaneously firing neurons in the preoptic-anterior hypothalamus, however, are temperature insensitive. A classic neuronal model developed originally by Hammel (1965) proposes that it is the comparison between excitatory and inhibitory synaptic inputs from temperature-insensitive and warm-sensitive neurons that provides the basis for set point temperatures in heat loss, heat retention, and heat production responses. Therefore, if the warm-sensitive neurons are considered the "heat sensors" of the thermoregulatory system, temperature-insensitive neurons would provide the "thermostat setting," and the error-detecting neurons (some times referred to as cold-sensitive neurons), which receive synapses from these two types of neurons, would be the "thermostat" of the system.

Modulation of the firing rate of any of these three types of neurons by neurotransmitter receptor agonist activation of GIRK2-containing channels could potentially influence pharmacologically induced hypothermic responses. Hyperpolarization produced by the activation of GIRK2-containing channels could either decrease or increase the firing rate of spontaneously firing neurons depending on whether the activated channels are located presynaptically or postsynaptically. For example, Strecker et al. (2000) found that adenosine, which has been shown to have direct inhibitory effects on many neurons, in fact activates neurons in the preoptic-anterior hypothalamus. The ability of adenosine to increase the firing rate of these neurons was explained by a reduction in GABAergic inhibitory input via presynaptic disinhibition.

Various experimentally testable hypotheses to explain our results can be derived from the thermoregulation model of Hammel (1965). In the simplest scenario, GPCR-mediated activation of presynaptic GIRK2-containing channels would induce hypothermia by a transient increase in the firing rate of warm-sensitive neurons. A less-straightforward scheme would involve a GIRK2mediated deceleration of the rate of recovery from hypothermia. In such a scheme, hypothermia would be induced by a separate GPCR-mediated mechanism (such as inhibition of voltage-gated calcium conductances or modulation of adenylyl cyclase activity). Although this mechanism is less intuitive than the first one, it can accommodate more easily the existence of hypothermia induced by agonists of GPCRs not shown to be linked to GIRK conductances (e.g., the 5- $\mathrm{HT}_{7}$ receptor, which modulates adenylyl cyclase activity) (Hedlund et al., 2003). It can also account directly for the observed shift to the left in the peak of the hypothermic response to 8-OH-DPAT of Girk2 KO compared with wild-type mice (Fig. 1A). We have observed similar shifts in the peak responses for baclofen, oxotremorine, 7-OH-DPAT, $R$-PIA, and ethanol (data not shown). (Clonidine produced no shift in peak response, and loperamide produced a shift to the right.)

One possible way of interpreting the observed shifts in the 
peak response involves the use of a simple dynamic scheme in which hypothermic responses are described in terms of the following transitions: normal body temperature $\rightarrow$ hypothermia $\rightarrow$ recovery. If GIRK2-containing channels play a significant role in hypothermia induction, a decrease in the expression of these channels should lead to a decrease in the rate of transition from normal body temperature to hypothermia and, therefore, a shift to the right and a decrease in amplitude of the peak response. However, if GIRK2-containing channels play a role in decreasing the rate of recovery from hypothermia, decreasing the expression of this gene should speed up recovery and produce a peak response that is smaller and shifted to the left in $\mathrm{KO}$ mice compared with wild-type animals. However, we should reemphasize that, because of the large number of pharmacokinetic variables associated with the type of experiment we have performed, direct interpretation of the resulting data in terms of molecular kinetics has only limited heuristic value. Future experiments involving in vivo microdialysis and simultaneous temperature measurements by radiotelemetry could potentially overcome this technical barrier and allow the distinction between the two competing mechanisms. In addition, future in vitro electrophysiological assessments of thermoregulatory neurons in the preoptic-anterior hypothalamus of Girk2 KO mice could complement such studies and provide a clear molecular mechanism for the central role of GIRK2-containing potassium channels in pharmacologically induced hypothermia.

Finally, we should note that, because the GIRK2 gene is located in human chromosome 21 (and its mouse ortholog, Girk2, is in mouse chromosome 16) (The Jackson Laboratory, 2005), our findings might be relevant to the study of neurotransmission and thermoregulation in persons with Down syndrome and aneuploid mouse models for this genetic disorder (for review, see Patterson and Costa, 2005).

\section{References}

Anderson R, Sheehan MJ, Strong P (1994) Characterization of the adenosine receptors mediating hypothermia in the conscious mouse. Br J Pharmacol 113:1386-1390.

Baker AK, Meert TF (2002) Functional effects of systemically administered agonists and antagonists of mu, delta, and kappa opioid receptor subtypes on body temperature in mice. J Pharmacol Exp Ther 302:1253-1264.

Eltayb A, Lindblom S, Oerther S, Ahlenius S (2001) Additive hypothermic effects of the 5-HT1A receptor agonist 8-OH-DPAT and the dopamine D2/3 receptor agonist 7-OH-DPAT in the rat. Acta Physiol Scand 172:205-209.

Gainetdinov RR, Bohn LM, Walker JK, Laporte SA, Macrae AD, Caron MG, Lefkowitz RJ, Premont RT (1999) Muscarinic supersensitivity and impaired receptor desensitization in $G$ protein-coupled receptor kinase 5-deficient mice. Neuron 24:1029-1036.

Hammel HT (1965) Neurons and temperature regulation. In: Physiological controls and regulations (Yamamoto WS, Brobeck JR, eds), pp 71-97. Philadelphia: Saunders.
Hedlund PB, Danielson PE, Thomas EA, Slanina K, Carson MJ, Sutcliffe JG (2003) No hypothermic response to serotonin in 5-HT7 receptor knockout mice. Proc Natl Acad Sci USA 100:1375-1380.

Heisler LK, Chu HM, Brennan TJ, Danao JA, Bajwa P, Parsons LH, Tecott LH (1998) Elevated anxiety and antidepressant-like responses in serotonin 5-HT1A receptor mutant mice. Proc Natl Acad Sci USA 95:15049-15054.

Jackson Laboratory (2005) Mouse genome informatics. Bar Harbor, ME: The Jackson Laboratory, http://www.informatics.jax.org/.

Jackson HC, Nutt DJ (1991) Inhibition of baclofen-induced hypothermia in mice by the novel GABAB antagonist CGP 35348. Neuropharmacology 30:535-538.

Krapivinsky G, Gordon EA, Wickman K, Velimirovic B, Krapivinsky L, Clapham DE (1995) The G-protein-gated atrial $\mathrm{K}^{+}$channel $\mathrm{I}_{\mathrm{KACh}}$ is a heteromultimer of two inwardly rectifying $\mathrm{K}^{+}$-channel proteins. Nature 374:135-141.

Lewohl JM, Wilson WR, Mayfield RD, Brozowski SJ, Morrisett RA, Harris RA (1999) G-protein-coupled inwardly rectifying potassium channels are targets of alcohol action. Nat Neurosci 2:1084-1090.

Malberg JE, Seiden LS (1997) Administration of fenfluramine at different ambient temperatures produces different core temperature and 5-HT neurotoxicity profiles. Brain Res 765:101-107.

Meller E, Chalfin M, Bohmaker K (1992) Serotonin 5-HT1A receptormediated hypothermia in mice: absence of spare receptors and rapid induction of tolerance. Pharmacol Biochem Behav 43:405-411.

Millan MJ, Dekeyne A, Newman-Tancredi A, Cussac D, Audinot V, Milligan G, Duqueyroix D, Girardon S, Mullot J, Boutin JA, Nicolas JP, RenouardTry A, Lacoste JM, Cordi A (2000) S18616, a highly potent, spiroimidazoline agonist at alpha(2)-adrenoceptors. I. Receptor profile, antinociceptive and hypothermic actions in comparison with dexmedetomidine and clonidine. J Pharmacol Exp Ther 295:1192-1205.

Patterson D, Costa ACS (2005) Down syndrome and genetics-a case of linked histories. Nat Rev Genet 6:137-147.

Popova NK, Ivanova EA (2002) 5-HT(1A) receptor antagonist p-MPPI attenuates acute ethanol effects in mice and rats. Neurosci Lett 322:1-4.

Signorini S, Liao YJ, Duncan SA, Jan LY, Stoffel M (1997) Normal cerebellar development but susceptibility to seizures in mice lacking G proteincoupled, inwardly rectifying K+ channel GIRK2. Proc Natl Acad Sci USA 94:923-927.

Strecker RE, Morairty S, Thakkar MM, Porkka-Heiskanen T, Basheer R, Dauphin LJ, Rainnie DG, Portas CM, Greene RW, McCarley RW (2000) Adenosinergic modulation of basal forebrain and preoptic:anterior hypothalamic neuronal activity in the control of behavioral state. Behav Brain Res 115:183-204.

Torrecilla M, Marker CL, Cintora SC, Stoffel M, Williams JT, Wickman K (2002) G-protein-gated potassium channels containing Kir3.2 and Kir3.3 subunits mediate the acute inhibitory effects of opioids on locus ceruleus neurons. J Neurosci 22:4328-4334.

Wickman K, Karschin C, Karschin A, Picciotto M, Clapham D (2000) Brain localization and behavioral impact of the G-protein-gated $\mathrm{K}^{+}$channel subunit GIRK4. J Neurosci 20:5608-5715.

Yamada M, Inanobe A, Kurachi Y (1998) G protein regulation of potassium ion channels. Pharmacol Rev 50:723-757.

Zhao Y, Boulant JA (2005) Temperature effects on neuronal membrane potentials and inward currents in rat hypothalamic tissue slices. J Physiol (Lond) 564:245-257. 